\title{
Who are those happy elderly people?
}

\author{
Eunhee Lee1)
}

\begin{abstract}
The present study was intended to analyse discriminant factors between happy and unhappy elderly people. For this purpose, 300 seniors in a metropolitan area in Korea were individually interviewed regarding subjective well-being, economic and health state, extraversion, neuroticism, self-esteem, goal instability, generativity, and social support. The discriminant factors between high emotional well-being elderly and low emotional well-being elderly were self-esteem, neuroticism, and goal instability. The discriminat factors between high life satisfaction elderly and low life satisfaction elderly were self-esteem and economic state. In conclusion, it was found that self-esteem served as the strongest discriminant factors between happy and unhappy elderly people.
\end{abstract}

Keywords : Happy elderly, Self-esteem, Neuroticism, Goal instability

\section{Introduction}

Who are those happy elderly and who are those unhappy elderly? As the life expectancy after retirement has increased dramatically in developed countries, this question has intrigued lay people and researchers as well. People generally believe happy elderly people are those who are affluent (at least not poor), mentally and physically healthy, having good social network, content with their life time achievement, have work to do and enjoy life. As psychology expands its inquiry into well-being of elderly as the aging society has become a reality, this question has been widely addressed by many psychologists[1-3]. Many concepts have been applied and identified to differentiate happy from unhappy elderly. Among them most notable concepts are subjective well being, self-esteem, goal instability, generativity, extroversion, neuroticism, and social support. Researches have shown that, compared to the unhappy elderly, the happy elderly is experiencing more positive emotions than negative emotions, tends to be more extroverted[1][4], have higher level of self-esteem[4-8], sense of goal directed activities[9],

Received(April 23, 2018), Review Result(1st: May 7, 2018, 2nd: May 28, 2018), Accepted(June 7, 2018)

${ }^{1}$ Dept. Psychology, Kyungnam Univ., 7 Kyungnamdaehak-ro, Masanhappo-gu, Changwon-si, Gyeongsangnam-do, 51767, Korea

email: ehlee@kyungnam.ac.kr 
greater sense of generativity[10-12], lower tendency of neuroticism[2][7], and higher level of social support[4][5][11][13-15]. An empirically interesting question is what are the most important ones among these many variables. Since most researchers regard their variables of interest as the important determinants of elderly's happiness, the answer depends on the perspective taking. Therefore, it makes practically more sense to ask what the sufficient set of variables is to account for elderly's happiness. To learn more about the happiness of the elderly people, The present study is an attempt to derive a pragmatic model for differentiating happy elderly from unhappy elderly.

\section{Method}

\subsection{Partcipants \& Procedures}

Participants consisted of 500 elderly people recruited from two senior centers located in two cities in Korea. Data from 300 people in a city were used to derive a discriminant function. The remaining 200 people from another city served to validate the discriminant function. For the first sample the average age was $74.6(\mathrm{sd}=5.04)$ and the majority was female $(265,89 \%)$. For the second sample, the average age was $73.9(\mathrm{sd}=5.24)$ and female was little over the half $(107,54 \%)$.

\subsection{Measures}

Emotional well-being was originally developed by Andrew and Withey[16] and translated into Korean language by Cha[17]. The scale consisted of four positive (happiness, love, pride, \& satisfaction) and four negative (fear, sadness, anger, \& guilt) emotions. The reliability index for internal consistency was .90 for the positive emotions and .79 for the negative emotions in the present study. Index of emotional well-being was obtained for use by subtracting total score for negative affect from total positive score. Life satisfaction, originally developed by Diener, Emmons, Larsen, and Griffin[18], was translated into Korean language by Cha[17]. The reliability index for internal consistency was .87 in the present study. A Korean translated[19] version of the Rosenberg's'[20] global self-esteem scale was used. The reliability index for internal consistency was .85 in the present study. The goal instability scale, developed by Robbins and Patten[21], was translated into Korean language by Lee[22]. The reliability index for internal consistency was .85 in the present study. We took scales for neuroticism and extraversion out of 
the Korean version of NEO PI-R, which was developed based on the original 5 factor personality scale by Costa and McCrae[23]. The reliability index for internal consistency was .79 for the extraversion and .80 for the neuroticism in the present study. The participants answered on 5 point scales their subjective evaluation of income level (very poor-very affluent), their health(very poor-very good), and relations with friends(very bad - very good).

\subsection{Statistical Analyses}

Before conducting multivariate analysis, we examined the multivariate normality of the data following the suggestions made by Tabachnick and Fidell[24]. Five cases (2 from the first sample and 3 from the second sample) were appeared to be multivariate outliers and deleted subsequently from the analysis. Since the assumption of homogeneity of variance-covariance for the first sample was violated, we used covariance matrices of within group to classify the groups mathematically adopting the second discriminant function. For the second sample which was used for cross validation, the homogeneity assumption appeared valid justifying the use of pooled covariance matrix. Therefore, the first discriminant function was used for classification. Using the scores of emotional well-being, calculated by subtracting the negative emotion experience from the positive emotion experience, we picked up those people whose score was one standard deviation (SD) higher or lower than the mean. Accordingly, 36 people were grouped as emotionally unhappy and 40 as happy from the first sample of 298. The scores of life satisfaction was used the same way to yield 37 unsatisfied and 31 satisfied from the first sample.

\section{Result}

A discriminant analysis was carried out for each criterion variable using all the predictor variables. For those two groups differing in emotional well-being, the discriminant function was able to classify $96.2 \%$ people correctly, yielding eta square of $73.7 \%$. A stepwise discriminant analysis showed that three predictors are sufficiently enough to correctly classify $94.7 \%$ of the people on the emotional well-being. Self-esteem, neuroticism, and goal instability constitute the discriminant function. The canonical correlation between the three predictors and the groups is .856 , and eta square is $73.4 \%$ (Table 1 \& 2). 
Who are those happy elderly people?

[Table 1] Stepwise Discriminant Function Analysis Classifying Emotional Well-being Level

\begin{tabular}{clclcc}
\hline Step & \multicolumn{1}{c}{ Included Predictor } & Wilk's $\lambda$ & $\mathrm{F}^{*}$ & $\mathrm{p}$ \\
\hline 1 & Self-Esteem & .37 & 122.84 & $<$ & .001 \\
2 & Neuroticism & .29 & 19.69 & $<.001$ \\
3 & Goal Instability & .27 & 5.89 & .018 \\
4 & Social Support from Family & .26 & 3.27 & .075 \\
\hline
\end{tabular}

* Degree of freedom for each F statistics is $(1,74),(2,73),(3,72)$, and $(4,71)$ each step.

[Table 2] Classification Results When the Self-esteem, Neuroticism and Goal Instability Were Used as Predictors

\begin{tabular}{c|c|c|c}
\hline \multirow{2}{*}{ Actual Group } & \multirow{2}{*}{$\begin{array}{c}\text { No. of } \\
\text { cases }\end{array}$} & \multicolumn{2}{|c}{ Predicted Group Membership } \\
\cline { 3 - 4 } & 36 & $\begin{array}{c}\text { Low Emotional Well-being } \\
(94.44 \%)\end{array}$ & High Emotional Well-being \\
\hline $\begin{array}{c}\text { Low emotional } \\
\text { well-being }\end{array}$ & 36 & 2 \\
\hline $\begin{array}{c}\text { High emotional } \\
\text { well-being }\end{array}$ & 40 & 2 & $(5.56 \%)$ \\
\hline
\end{tabular}

Note. Percentage of grouped cases correctly classified is $94.72 \%$.

For the two groups differing in life satisfaction, a stepwise discriminant analysis showed that self-esteem and income level perception are enough to classify $91.4 \%$ people correctly. The canonical correlation between the discriminant function with two variables and the groups turns out .84 , yielding eta square of $70.1 \%$ (Table $5 \& 6$ ).

[Table 3] Stepwise Discriminant Function Analysis Predicting Life Satisfaction Level

\begin{tabular}{ccccc}
\hline Step & Included Predictor & Wilk's $\lambda$ & $\mathrm{F}^{*}$ & $\mathrm{p}$ \\
\hline 1 & Self-Esteem & .32 & 139.47 & $<.001$ \\
2 & Subjective Evaluation of Income Level & .30 & 4.55 & .037 \\
3 & Social Support from Family & .28 & 2.90 & .094 \\
\hline
\end{tabular}

* Degree of freedom for each F statistics is $(1,66),(2,65)$, and $(3,64)$ each step.

[Table 4] Classification Results When the Self-esteem and Subjective Evaluation of Income Level Were Used as Predictors

\begin{tabular}{cccc}
\hline \multirow{2}{*}{ Actual Group } & \multirow{2}{*}{ No. of Cases } & \multicolumn{2}{c}{ Predicted Group Membership } \\
\cline { 3 - 4 } & & Low Life Satisfaction & High Life Satisfaction \\
\hline Low life & 37 & 33 & 4 \\
Satisfaction & & $(89.19 \%)$ & $(10.81 \%)$ \\
High Life & 31 & 2 & 29 \\
Satisfaction & & $(6.45 \%)$ & $(93.55 \%)$ \\
\hline
\end{tabular}

Note. Percentage of grouped cases correctly classified is $91.37 \%$. 
Since the stepwise discriminant analysis is highly subject to sample characteristics, a cross-validation is highly recommended. For cross-validation we applied the discriminant function to independent set of people. 200 elderly people from a senior center in another city served for this purpose. This people filled out the questionnaire given to the first sample. On each of the two criterion measures, two groups of people were identified by using the 1 standard deviation method, as previously stated. The discriminant function of three predictor variables (self-esteem, neuroticism, and goal stability) classified correctly 95.9\% of those high and low emotional well-being. The discriminant function of two predictor variables (self-esteem, perception of income level) classified correctly $91.8 \%$ of those high and low life satisfaction. The results show the two discriminant functions have sufficient cross-validity in classifying elderly people distinctively high or low in emotional well-being and in life satisfaction.

\section{Findings and Conclusion}

The present investigation attempted to pull out discriminant functions to classify happy people and unhappy people. Two criteria variables of subjective well-being were independently used for discriminant analysis. Individually tested, the variables of extraversion, neuroticism, self-esteem, generativity, goal instability, income level, health, and friendship are all shown to be differentiating happy and unhappy people. But three variables, self-esteem, neuroticism, and goal instability are able to represent most variances of emotional well-being. Discriminant function of 11 variables accounted for $74.4 \%$ of variances but the function of three variables remarkably accounted for $73.4 \%$. In the analysis of life satisfaction, the discriminant function of 11 variables pulled out $73.7 \%$ but a function of two variables, self-esteem and perceived income level, are able to pull out most variances $(70.1 \%)$. The two discriminant functions are shown to have sufficient cross-validity in different sample of elderly people. The present results indicate that, among many variables, self-esteem is the foremost variable differentiating happy and unhappy people. The current result confirms that neuroticism is a significant factor affecting mainly emotional well-being and shows that goal instability exerts important role in securing emotional well-being.

Although the results look impressive, the present analysis is not based on theoretical reasoning. Discussions are needed to understand the findings.

Role of self-esteem The present results indicate that, among many variables, self-esteem is the foremost variable differentiating happy and unhappy people. Indeed, self-esteem alone can pull out $63 \%$ of variances for emotional well-being and $68 \%$ of variances for life satisfaction. The 
nature of stepwise statistical analysis adopted here tells us that self-esteem may represent other variables of significance which are regarded important in separate investigations. Therefore it is reasonably expected that people with self-esteem are more likely to experience more instances of positive emotions, less of negative emotions, and greater level of life satisfaction. Self-esteem seems essential for self-determination[25] and serves to form and maintain satisfactory social relationships[26]. Given all the reasoning and evidences, it comes as no surprise that psychologists regard the maintenance and enhancement of self-esteem as a primary motive for human behavior[27][28].

Neuroticism Many studies treated neuroticism as an important personality predictor for subjective well being[2][29]. Eysenck[30] hypothesized that neuroticism represents susceptibility to negative affect. That is, individuals high in neuroticism are more vulnerable to threatening life events and are likely to fall victim of them. There is evidence that stable personality traits can dispose people to experience moderately stable level of favorable and adverse life events and subjective well-being[31]. The current result confirms that neuroticism is a significant factor affecting mainly emotional well-being.

Goal instability. The present analysis shows that goal instability exerts important role in securing emotional well-being. People with high goal instability tend to lack orienting goals and values[32]. Goal instability significantly accounted for adjustment and well-being after injury causing disability[33]. It has been shown to influence depression and social satisfaction among elderly[34]. The present result confirms this.

In conclusion, the current study shows that, compared to the unhappy elderly, the happy elderly have higher level of self-esteem, lower tendency of neuroticism, higher sense of goal directedness, and higher level of income. The present study provides intervention strategies for improving mental wellbeing in Korean elderly people via field research. More research is needed to identify other variables associated with Korean elderly people's mental wellbeing.

\section{References}

[1] M. Argyle, in Well-being: The foundation of hedonic psychology, Edited D. Kahneman, E. Diener, and N. Schwarz, Russell Sage Foundation, New York, USA (1999), Causes and correlates of happiness, pp. 353-373.

[2] S. M. A. Lamers, G. J. Westerhof, V. Kovács and E. T. Bohlmeijer, Differential relationships in the association of the Big Five personality traits with positive mental health and psychopathology, Journal of Research in Personality (2012), Vol.46, No.5, 517-524. 
[3] D. G. Myers and E. Diener, Who is Happy?, Psychological Science (1995), Vol.6, No.1, pp.10-19.

[4] M. Kim and J. Ko, Study on the Determinants of Life Satisfaction among the Elderly: An Integrative Approach, International Journal of Contents (2013), Vol.13, No.6, 246-259.

[5] M. S. Chang and K. S. Park, Factors Affecting Life Satisfaction for the Aged: From the Ecosystem Perspective, Health and Social Welfare Review (2012), Vol.32, No.2, 232-266.

[6] M. Jung, The Influence of Participation in Social Activities of the Elderly on Self-Esteem and Life Satisfaction, Korean Journal of Care Management (2013), Vol.9, pp.15-41.

[7] E. Lee, G. Kim, G. Han and R. Ju, Analysis of the Role of Generativityinthe Subjective Well-Being among Elderly Adults, Journal of the Korea Gerontological Society (2004), Vol.24, No.3, pp.131-152.

[8] B. W. Leung, G. B. Moneta and C. McBride-Chang, Think Positively and Feel Positively: Optimism and Life Satisfaction in Late Life, The International Journal of Aging and Human Development (2005), Vol.61, No.4, pp.335-365.

[9] E. C. Payne, S. B. Robbins and L. Dougherty, Goal directedness and older-adult adjustment, Journal of Counseling Psychology (1991), Vol.38, No.3, pp.302-308.

[10] J. S. An and T. M. Cooney, Psychological well-being in mid to late life: The role of generativity development and parent-child relationships across the lifespan, International Journal of Behavior Development (2006), Vol.30, No.5, pp.410-421.

[11] Y. J. Cho, The Elderly Volunteers' Psychological Well-being - On the Effects of Old People's Generativity and Family Support -, Korean Journal of Human Ecology (2008), Vol.17, No.2, pp.191-205.

[12] D. P. McAdams and E. de St. Aubin and R. L. Logan, Generativity among young, midlife, and older adults, Psychology and Aging (1993), Vol.8, No.2, pp.221-230.

[13] B. C. Feeney and N. L. Collins, A New Look at Social Support: A Theoretical Perspective on Thriving Through Relationships, Personality and Social Psychology Review (2015), Vol.19, No.2, pp.113-147.

[14] E. Kahana, T. Bhatta, L. D. Lovergreen, B. Kahana and E. Midlarsky, Altruism, Helping, and Volunteering: Pathways to Well-Being in Late Life, Journal of Aging and Health (2013), Vol.25, No.1, 159-187.

[15] Y. Park and E. Noh, A Study on the Effects of Social Support on the Subjective Happiness of the elderly People, Journal of the Korean Academy of Health and Welfare for Elderly (2015), Vol.7, No.1, pp.37-48.

[16] F. M. Andrew and S. B. Withey, Developing measures of perceived life quality: Results from several national surveys, Social Indicators Research (1974), Vol.1, No.1, pp.1-26.

[17] K. Cha, Psychology of life quality among college students in Korea, Japan, and United States. Proceedings of the Spring Symposium of Korean Psychological Association, (1995) pp.113-143, May; Seoul, Korea

[18] E. Diener, R. A. Emmons, R. J. Larsen, and S. Griffin, The Satisfaction With Life Scale, Journal of Personality Assessment (1985), Vol.49, No.1, pp.71-75.

[19] B. Jon, Self-Esteem: A Test of Its Measurability, Yonsei Nonchong (1974), Vol.11, No.1, pp.107-130.

[20] M. Rosenberg, Society and the Adolescent Self-image, Princeton University Press, Princeton, N.J. (1965) 
[21] S. B. Robbins and M. J. Patten, Self-psychology and career development: Construction of the Superiority and Goal Instability scales, Journal of Counseling Psychology (1985), Vol.32, No.2, pp.221-231.

[22] E. Lee, The Role of Goal Instability and Resolving Style of Problems Between Nurses' Job Stressors and Emotional Exhaustion, The Korean Journal of Woman Psychology (2008), Vol.13, No.4, pp.397-413.

[23] P. T. Jr. Costa and R. R. McCrae, Revised NEO Personality Inventory (NEO PI-R) and NEO Five-Factor Inventory (NEO-FFI) professional manual, Psychological Assessment Resources, Odessa, FL (1992)

[24] B. G. Tabachnick and L. S. Fidell, Using multivariate statistics (5th ed.), Allyn \& Bacon/Pearson Education, New York USA (2007)

[25] E. L. Deci and R. M. Ryann, Human autonomy: The basis for true self-esteem, Edited M. H. Kernis, Plenum series in social/clinical psychology, New York, USA (1995), Efficacy, agency, and self-esteem, pp.31-49.

[26] M. R. Leary and R. F. Baumeister, The nature and function of self-esteem: Sociometer theory, Advances in Experimental Social Psychology (2000), Vol.32, pp.1-62.

[27] R. F. Baumeister, The self, Edited D. T. Gilbert, S. T. Fiske, and G. Lindzey, McGraw-Hill, New York, USA (1998), The handbook of social psychology, pp.680-740.

[28] C. Sedikides and M. J. Strube, Self-Evaluation: To Thine Own Self Be Good, To Thine Own Self Be Sure, To Thine Own Self Be True, and To Thine Own Self be Better, Advances in Experimental Social Psychology (1997), Vol.29, pp.209-269.

[29] P. T. Costa and R. R. McCrae, Influence of extraversion and neuroticism on subjective well-being: Happy and unhappy people, Journal of Personality and Social Psychology (1980), Vol.38, No.4, pp.668-678.

[30] M. W. Eysenck, Trait Theories of Anxiety, Edited J. Strelau and H. J. Eysenck, Plenum Press, New York, USA (1987). Personality Dimensions and Arousal, pp.79-97.

[31] B. Headey and A. Wearing, Personality, life events, and subjective well-being: Toward a dynamic equilibrium model, Journal of Personality and Social Psychology (1989), Vol.57, No.4, pp.731-739.

[32] M. J. Patton and S. B. Robbins, Kohut's self-psychology as a model for college-student counseling, Professional Psychology (1982), Vol.13, No.6, pp.876-882.

[33] T. R. Elliott, G. Uswatte, L. Lewis and A. Palmatier, Goal instability and adjustment to physical disability, Journal of Counseling Psychology (2000), Vol.47, No.2, pp.251-265.

[34] L. C. Smith and S. B. Robbins, Validity of the Goal Instability scale (modified) as a predictor of adjustment in retirement-age adults, Journal of Counseling Psychology (1988), Vol.35, No.3, pp.325-329. 